\title{
Erratum
}

\section{The challenges of control groups, placebos and blinding in clinical trials of dietary interventions}

\author{
Heidi M. Staudacher, Peter M. Irving, Miranda C.E. Lomer and Kevin Whelans
}

doi: 10.1017/S0029665117000350, Published by Cambridge University Press, 20 June 2017

We regret to announce that the name of one of the authors listed above was spelled incorrectly in the published paper. Kevin Whelans should have been spelled Kevin Whelan. The publishers apologise for this error.

\section{Reference}

Staudacher H.M., Irving P.M., Lomer M.C.E. \& Whelans K. (2017) The challenges of control groups, placebos and blinding in clinical trials of dietary interventions. Proc Nutr Soc, published online by Cambridge University Press 20 June 2017, doi 10.1017/ S0029665117000350 